\title{
BMJ Open Retrospective cohort study of all deaths among infants born between 22 and 27 completed weeks of gestation in Switzerland over a 3-year period
}

\author{
T M Berger, ${ }^{1}$ M A Steurer, ${ }^{2} \mathrm{H}$ U Bucher, ${ }^{3} \mathrm{~J}$ C Fauchère, ${ }^{3}$ M Adams, ${ }^{3}$ R E Pfister, ${ }^{4}$ \\ R Baumann-Hölzle, ${ }^{5}$ D Bassler, ${ }^{3}$ on behalf of the Swiss Neonatal End-of-Life Study \\ Group
}

To cite: Berger TM, Steurer MA, Bucher HU, et al. Retrospective cohort study of all deaths among infants born between 22 and 27 completed weeks of gestation in Switzerland over a 3-year period. BMJ Open 2017;7:e015179. doi:10.1136/ bmjopen-2016-015179

- Prepublication history and additional material are available. To view these files please visit the journal online (http://dx.doi. org/10.1136/bmjopen-2016015179).

Received 18 November 2016 Revised 28 February 2017 Accepted 6 April 2017

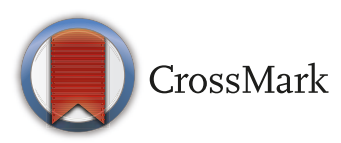

${ }^{1}$ Neonatal and Paediatric Intensive Care Unit, Children's Hospital Lucerne, Lucerne, Switzerland

${ }^{2}$ Division of Pediatric Critical Care, Department of Pediatrics, University of California Medical Center, San Francisco, California, USA

${ }^{3}$ Department of Neonatology, University Hospital Zurich and University of Zurich, Zurich, Switzerland

${ }^{4}$ Division of Neonatology and Paediatric Intensive Care, Children's University Hospital Geneva, Geneva, Switzerland ${ }^{5}$ Dialogue Ethics Foundation, Interdisciplinary Institute for Ethics in Health Care, Zurich, Switzerland

Correspondence to

Dr T M Berger;

tmberger@bluewin.ch

\section{ABSTRACT}

Objectives The aim of this research is to assess causes and circumstances of deaths in extremely low gestational age neonates (ELGANs) born in Switzerland over a 3-year period.

Design Population-based, retrospective cohort study. Setting All nine level III perinatal centres (neonatal intensive care units (NICUs) and affiliated obstetrical services) in Switzerland.

Patients ELGANs with a gestational age $(\mathrm{GA})<28$ weeks who died between 1 July 2012 and 30 June 2015.

Results A total of 594 deaths were recorded with 280 $(47 \%)$ stillbirths and $314(53 \%)$ deaths after live birth. Of the latter, $185(59 \%)$ occurred in the delivery room and $129(41 \%)$ following admission to an NICU. Most liveborn infants dying in the delivery room had a $\mathrm{GA} \leq 24$ weeks and died following primary non-intervention. In contrast, NICU deaths occurred following unrestricted life support regardless of GA. End-of-life decision-making and redirection of care were based on medical futility and anticipated poor quality of life in $69 \%$ and $28 \%$ of patients, respectively. Most infants were extubated before death (87\%).

Conclusions In Switzerland, most deaths among infants born at less than 24 weeks of gestation occurred in the delivery room. In contrast, most deaths of ELGANs with a $\mathrm{GA} \geq 24$ weeks were observed following unrestricted provisional intensive care, end-of-life decision-making and redirection of care in the NICU regardless of the degree of immaturity.

\section{INTRODUCTION}

Ongoing progress in perinatal care has lead to unprecedented survival rates for extremely low gestational age neonates (ELGANs) Survival of infants who were considered to be marginally viable 30 years ago has now become the rule rather than the exception. ${ }^{1-4}$ In parallel, neonatologists have continued to push the limit of viability to lower and lower gestational ages (GAs). However, this success has its price and the burden of intensive care imposed on borderline viable infants who
Strengths and limitations of this study

- The current study provides a comprehensive assessment of end-of-life decision-making in extremely low gestational age neonates (ELGANs) born in all level III perinatal centres in Switzerland over a 3-year period.

- Since all deaths (including delivery room (DR) deaths, stillbirths and late terminations of pregnancy) were included in this study, differences in end-of-life decision-making between DR and NICU deaths could be analysed.

- Data collection was restricted to level III perinatal centres and therefore ELGANs who have died at lower level institutions may have been missed.

- Even though almost 600 deaths were included in the study, the sample size was too small to allow for centre comparison.

ultimately do not survive and high rates of neurosensory impairments among survivors have raised serious ethical questions. ${ }^{5-9}$ Many national paediatric and neonatal societies have responded to these concerns with the publication of guidelines to support ethical decision-making in the care of borderline viable infants. ${ }^{10-16}$

Swiss obstetricians and neonatologists have traditionally had a more restrictive attitude towards providing proactive care for infants born at the limit of viability. Quality of life considerations have always had a high priority. Consequently, mortality rates of ELGANs in Switzerland are higher compared with some, but not all, highly developed countries. ${ }^{17}$

Following the publication of the first Swiss recommendations for the care of infants born at the limit of viability (22-26 weeks) in 2002, ${ }^{10}$ improved survival rates for infants born at 25 completed weeks of gestation were demonstrated in some but not all centres. ${ }^{1819}$ 
The Swiss guidelines were revised in $2011 .{ }^{20}$ They emphasise the fact that apart from stratification by GA, additional factors significantly affecting prognosis (ie, estimated fetal weight, sex, exposure or non-exposure to antenatal corticosteroids, single or multiple births) must be considered. The grey zone is more narrowly defined (24 0/7-24 $6 / 7$ weeks of gestation) but its borders are not absolute allowing for an individualised approach in the perinatal care at the limit of viability. The impact of the revised guidelines on end-of-life decision-making is unknown.

The aim of the current study was to examine the reasons for end-of-life decision-making and circumstances of death in ELGANs born in Switzerland over a 3-year period following the publication of the revised guidelines.

\section{METHODS}

Detailed information on all delivery room (DR) and neonatal intensive care unit (NICU) deaths before discharge among ELGANs with a GA between 22 to 27 completed weeks born in Switzerland over a 36-month-period (1 July 2012 to 30 June 2015) was collected. Both stillborn and liveborn infants were included. Data collection was organised on-site in the level III NICUs at the University Hospitals of Basel, Bern, Geneva, Lausanne and Zurich, and the level III NICUs at the Cantonal Hospitals of Aarau, Chur, Lucerne and St. Gallen. Switzerland has a well-developed system of regionalised care, and the vast majority of ELGANs $(>90 \%)$ are born in one of these perinatal centres.

Patients were identified using clinical records, electronic databases as well as birth log books. Deidentified data were entered by trained research assistants on-site into REDCap (Research Electronic Data Capture), a secure online database. The system featured easy-to-use online screen forms and electronic data validation checks to minimise data-entering errors. Confidentiality was assured by password protection.

For each patient, date and time of birth as well as the perinatal centre where the infant was born were registered. Additional demographic data included GA in weeks and days, birth weight, sex and whether the infant was a singleton or child from a multiple birth. Pregnancy complications such as premature rupture of membranes, clinical chorioamnionitis and maternal hypertension were recorded. The use of prenatal steroids as well as the type of delivery were assessed. Deliveries occurring after spontaneous labour or induction of labour for maternal reasons or with the objective to increase chances of infant survival were distinguished from late terminations of pregnancy.

For stillborn infants, apart from basic demographic data, it was assessed whether labour occurred spontaneously or was induced for late termination of pregnancy. For liveborn infants, DR resuscitation measures (intubation, use of surfactant, chest compressions, use of epinephrine) were noted. The reason for death in the DR was classified as either primary non-intervention, limited resuscitation or full resuscitation. For infants who received palliative care only, the use of sedatives or analgesics was recorded.

For infants admitted to the NICU, information on severe neonatal complications (ie, periventricular/intraventricular haemorrhage, cystic periventricular leukomalacia, persistent ductus arteriosus requiring medical or surgical therapy, air leak, necrotising enterocolitis, focal intestinal perforation, sepsis and renal failure) and age at death were noted. Daily data on cardiovascular and respiratory system performance as well as the degree of cardiorespiratory support were recorded for 3 days prior to death. Based on this information, it was determined whether the primary cause of death was related to severe congenital malformations, refractory cardiovascular or respiratory failure, sepsis, gastrointestinal complications or severe neurological injury. In doubtful cases, the data were reviewed by the principal investigator (TMB) for final classification. In addition, it was recorded whether death occurred despite ongoing unrestricted intensive care or whether death was preceded by withholding or withdrawing of life-sustaining therapies. Reasons for any redirection of care (ROC) decisions were classified as being due to medical futility or concerns regarding the anticipated future quality of life. Finally, the use of any medication to alleviate pain and suffering after ROC was noted.

\section{Statistical analyses}

Continuous variables are presented as median and IQR, dichotomous variables are presented as absolute numbers and percentages. Mann-Whitney $\mathrm{U}$ test was used to compare medians and $\chi^{2}$ test was used to compare proportions. Kruksal-Wallis analysis of variance was used to compare $>2$ medians. A p value of $<0.05$ was considered significant. Kaplan-Meier curves were drawn to compare survival time in days by reason for redirection of care. Statistical analyses were performed using Stata V.13.

\section{RESULTS}

\section{All deaths}

Overall, 594 deaths of ELGANs were recorded over the 3-year study period. Of these, $280(47 \%)$ infants were stillborn (median GA and birth weight 23 5/7 weeks and $537 \mathrm{~g}$, respectively) and 314 (53\%) died after live birth. Of the latter, 185 (59\%) died in the DR, and $129(41 \%)$ died in the NICU following provisional intensive care (figure 1). Median GA and birth weight were higher in the infants who died in the NICU (25 2/7 weeks and 690 g) than in infants who were born alive but died in the DR (23 3/7 weeks and $560 \mathrm{~g}, \mathrm{p}<0.01$ for both GA and birth weight). Infants who died in the NICU had a higher rate of exposure to prenatal steroids $(\mathrm{p}<0.01)$ and were more commonly born by Caesarean section $(\mathrm{p}<0.01) \quad(88 \%$ and $64 \%$, respectively) compared with liveborn infants who died in the DR (10\% and $11 \%$, respectively; data not collected for stillborn infants) (table 1). 


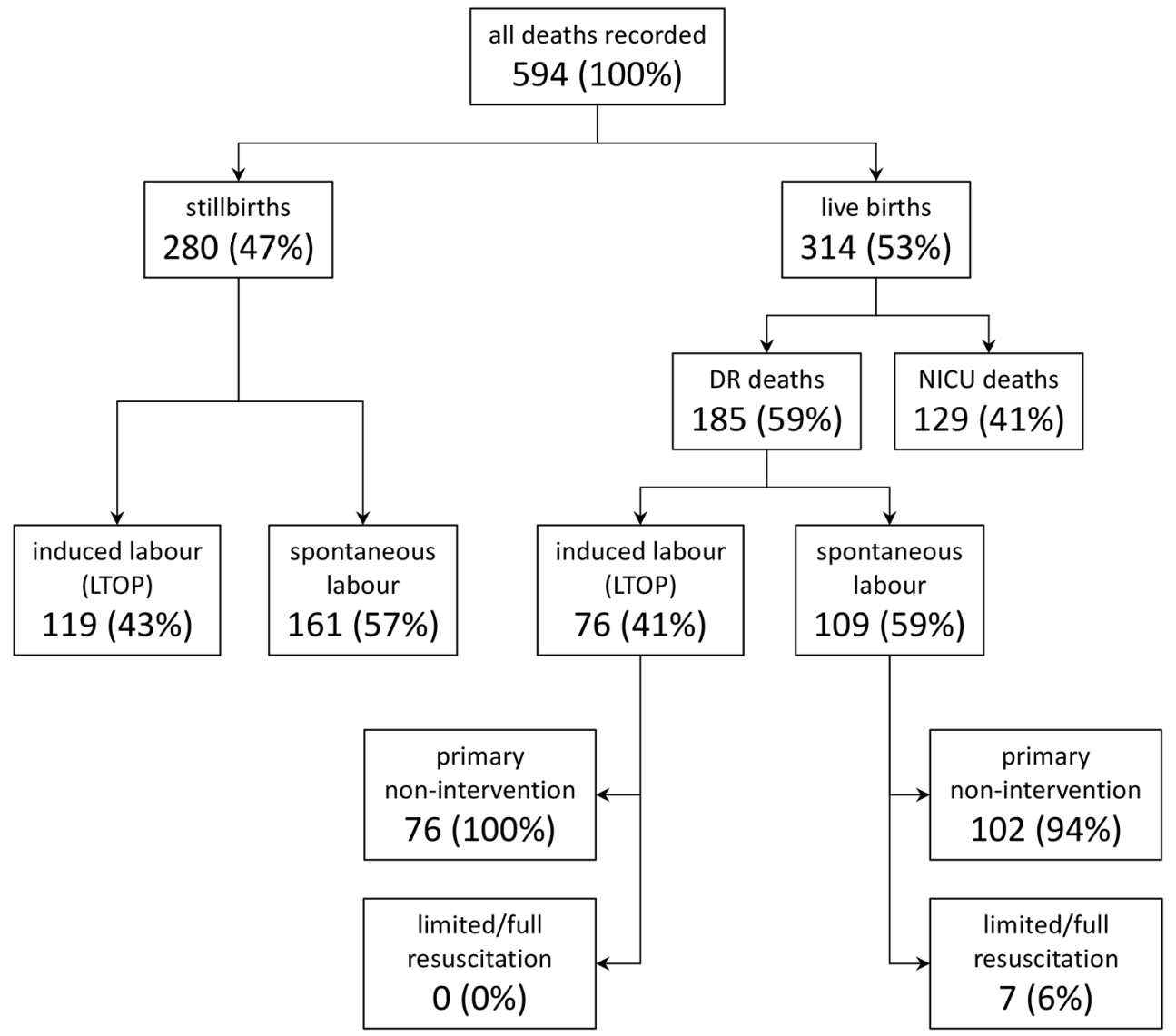

Figure 1 Overview of the study population $(n=594)$. DR, delivery room; LTOP, late termination of pregnancy; NICU, neonatal intensive care unit.

\begin{tabular}{|c|c|c|c|}
\hline & \multicolumn{3}{|l|}{ Liveborn infants $n=314$} \\
\hline & DR deaths & NICU deaths & p Value \\
\hline Patient characteristics & $n=185$ & $n=129$ & \\
\hline GA in weeks and days, median (IQR) & 23 3/7 (22 5/7-24 1/7) & 25 2/7 (24 3/7-26 3/7) & $<0.01$ \\
\hline Birth weight in grams, median (IQR) & $560(478-643)$ & $690(580-850)$ & $<0.01$ \\
\hline Female, n (\%) & $76(41)$ & $61(47)$ & 0.275 \\
\hline Multiplets, n (\%) & $45(24)$ & $39(30)$ & 0.245 \\
\hline Obstetrical interventions & $n=185$ & $n=129$ & \\
\hline Any prenatal steroids, n (\%) & $19(10)$ & $114(88)$ & $<0.01$ \\
\hline Caesarean delivery, n (\%) & $21(11)$ & $82(64)$ & $<0.01$ \\
\hline DR interventions & $n=109^{*}$ & $n=129$ & \\
\hline Primary non-intervention & $102(93)$ & NA & \\
\hline Limited resuscitation & $4(4)$ & NA & \\
\hline Full resuscitation & $3(3)$ & NA & \\
\hline Intubated in DR & $1(1)$ & $110(85)$ & $<0.01$ \\
\hline Surfactant in DR & $0(0)$ & $101(78)$ & $<0.01$ \\
\hline Epinephrine in DR & $1(1)$ & $5(4)$ & $<0.01$ \\
\hline
\end{tabular}

*Liveborn infants after late termination of pregnancy $(n=76)$ are not included.

$\mathrm{DR}$, delivery room; GA, gestational age; NA, not applicable; NICU, neonatal intensive care unit. 
Deaths after live birth following spontaneous labour or induction of labour for maternal reasons or with the objective to increase chances of infant survival

Obstetrical and DR interventions were used only rarely in liveborn ELGANs after spontaneous labour at 22 and 23 weeks, and almost all deaths occurred in the DR (22 weeks: 100\%, 23 weeks: 89\%). A more active approach was seen at 24 weeks and the proportion of DR deaths decreased to $35 \%$. At more than 24 weeks, the majority of deaths $(\geq 95 \%)$ were observed in the NICU (table 2 ).

\section{Circumstances of DR deaths}

Overall, 465 (78\%) of all deaths were recorded in the DR. Of these, 270 were born after spontaneous labour (161 $(60 \%)$ stillborn and 109 (40\%) live born) (figure 1). Regardless of GA, active perinatal interventions were used only in a minority of liveborn infants after spontaneous labour who later died in the DR. Failed resuscitation attempts were rare $(n=7)$ (table 1$)$. The remaining DR deaths $(n=195)$ occurred in the context of late termination of pregnancy. Of these, $119(61 \%)$ were stillborn and $76(39 \%)$ were born alive and died following primary non-intervention (figure 1). In all DR deaths, the use of drugs for palliative care was either rare or, alternatively, poorly documented.

\section{Circumstances of NICU deaths}

A total of 129 ELGANs died following NICU admission (22\% of all deaths recorded). To analyse whether the degree of immaturity had an impact on the circumstances of death in the NICU, two groups of ELGANs were compared: infants with a GA $<25$ weeks (group 1) and infants with a GA $\geq 25$ weeks (group 2).

For both groups, medical futility was the predominant reason given for end-of-life decision-making in the NICU (mentioned in $65 \%$ and $72 \%$ of group 1 and group 2 patients, respectively); quality-of-life considerations was the reason for ROC decisions in $33 \%$ and $26 \%$ of these patients (table 3 ).

Independent of their GA, most infants were on invasive respiratory support in the 3 days preceding death $(>90 \%)$; however, at the time of death, the majority $(\geq 85 \%)$ was extubated. The use of advanced life-sustaining therapies was comparable between the two groups. Cardiopulmonary resuscitation (CPR) within 12 hours of death was noted in 14 of the 129 patients who died in the NICU ( $7 \%$ and $13 \%$ in group 1 and group 2 infants, respectively). The use of morphine after ROC was common $(>50 \%)$; benzodiazepines, on the other hand, were administered in $\leq 15 \%$ of dying infants (table 3 ).

Among all infants admitted to NICU who ultimately did not survive, $50 \%$ had died by day of life 6 , and $75 \%$ by day of life 17. The age at death of ELGANs dying following ROC because of medical futility was comparable to that of ELGANs in whom life-sustaining therapies were withdrawn because of quality-of-life considerations (figure 2). Early deaths were observed in infants with severe neurological injury and refractory cardiovascular failure with
$50 \%$ having died on day of life 1 and 2, respectively. In contrast, $50 \%$ of ELGANs with severe congenital malformations, sepsis and refractory respiratory failure survived for more than 1 week. Finally, gastrointestinal complications were associated with the latest deaths with $50 \%$ having died by day of life 19 (table 4 ).

\section{DISCUSSION}

The results of the current study provide a comprehensive assessment of all deaths among infants born between 22 and 27 completed weeks of gestation in Switzerland over a 3-year period. Previous reports have been limited to Swiss single-centre experiences of neonatal deaths (preterm and term infants), and have excluded stillbirths ${ }^{21-23}$ or even all DR deaths, ${ }^{23}$ as well as deaths of infants with a GA below $23^{22}$ or 24 weeks. ${ }^{21}$

Antenatal and intrapartum stillbirths accounted for a large proportion $(47 \%)$ of all deaths among ELGANs. While some stillbirths cannot be prevented, others, particularly in the most immature ELGANs, will occur in the context of non-active obstetrical management. ${ }^{24}$ Stillbirths are inconsistently reported and thus constitute a significant hidden mortality. The time point at which researchers begin to observe outcomes (ie, their inception point) significantly influence outcome statistics for extremely preterm births. ${ }^{25}$

For infants dying following live birth after spontaneous labour, GA appeared to be the major factor when decisions about initiation of life-sustaining measures in the DR were made, leading to three distinct categories. First, at 22-23 weeks, proactive perinatal interventions were rarely used and preference was given to palliative care. Obviously, death was the planned and accepted outcome, and, consequently, the majority of deaths occurred in the DR ( $100 \%$ and $89 \%$ at 22 and 23 weeks, respectively). Second, at 24 weeks, a proactive approach became more common and deaths were distributed more evenly between the DR $(35 \%)$ or the NICU $(65 \%)$. Third, at GAs $\geq 25$ weeks, active care was the rule and the large majority of deaths $(\geq 95 \%)$ occurred in the NICU following a period of unrestricted intensive care. Our findings closely mirror the the results of the Etude Epidémiologique sur les Petits Ages Gestationnels (EPIPGAGE-2) study from France, which also demonstrated that decision-making in the DR was based almost exclusively on GA. ${ }^{26}$ In an accompanying editorial, Janvier and Lantos warned of the harms of the GA label and the fact that (restrictive) policies not only reflected outcomes but, in fact, would shape them. ${ }^{27}$

Given the high concordance between obstetrical and neonatal non-interventions, it appears that these decisions had been made prior to delivery and were rarely-if ever - revised after birth. These observations suggest that Swiss obstetricians and neonatologists consider a narrow window (ie, 24 weeks of gestation) as what has been described as the 'grey zone' of infant viability. ${ }^{28} 29$ This is largely consistent with the current Swiss guidelines on perinatal care at the limit of viability, which favour 


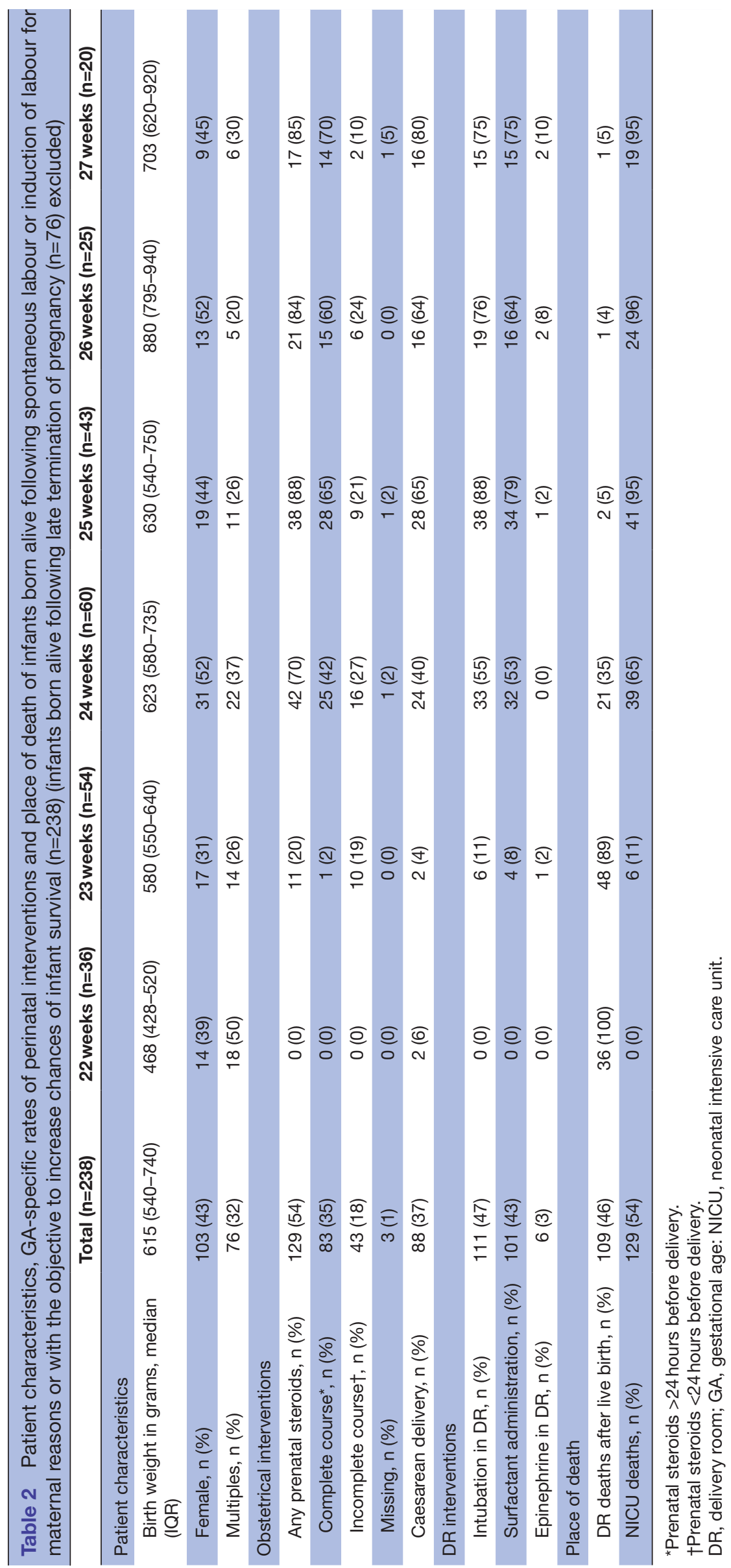


Table 3 Patient characteristics, reasons for end-of-life decisions and circumstances of death among infants admitted to the NICU ( $n=129)$

\begin{tabular}{|c|c|c|c|}
\hline Patient characteristics & $<25$ weeks $(n=45)$ & $\geq 25$ weeks $(n=84)$ & $\mathrm{p}$ Value \\
\hline GA in weeks and days, median (IQR) & 24 3/7 (24 1/7-24 4/7) & 26 0/7 (25 2/7-26 6/7) & $<0.0001$ \\
\hline Birth weight in grams, median (IQR) & $630(590-710)$ & $735(500-735)$ & $<0.0001$ \\
\hline Multiplets, n (\%) & $17(38)$ & $22(26)$ & 0.172 \\
\hline \multicolumn{4}{|l|}{ Reason for end-of-life decision } \\
\hline Medical futility, n (\%) & $29(65)$ & $60(72)$ & \\
\hline Missing, n (\%) & $1(2)$ & $2(2)$ & 0.69 \\
\hline \multicolumn{4}{|l|}{ Respiratory support within 3 days of death } \\
\hline No mechanical ventilation, $\mathrm{n}(\%)$ & $0(0)$ & $0(0)$ & \\
\hline CPAP only, $n(\%)$ & $0(0)$ & $2(2)$ & \\
\hline CMV, n (\%) & $18(40)$ & $44(52)$ & \\
\hline Maximum $\mathrm{FiO}_{2}$, mean (SD) & $0.77(0.24)$ & $0.8(0.29)$ & 0.75 \\
\hline \multicolumn{4}{|l|}{ Cardiovascular support within 3 days of death } \\
\hline Dopamine, n (\%) & $14(31)$ & $38(45)$ & 0.11 \\
\hline Maximum dopamine dose in $\mu \mathrm{g} / \mathrm{kg} / \mathrm{min}$, mean (SD) & $10(6)$ & $14(6)$ & 0.049 \\
\hline Epinephrine, n (\%) & $9(20)$ & $16(19)$ & 0.9 \\
\hline Maximum epinephrine dose in $\mu \mathrm{g} / \mathrm{kg} / \mathrm{min}$, mean (SD) & $0.5(0.5)$ & $0.4(0.3)$ & 0.5 \\
\hline CPR within 12 hours of death, $\mathrm{n}(\%)$ & $3(7)$ & $11(13)$ & 0.088 \\
\hline \multicolumn{4}{|l|}{ Circumstances after ROC } \\
\hline Intubated at time of death, $\mathrm{n}(\%)$ & $4(9)$ & $13(15)$ & 0.095 \\
\hline
\end{tabular}

$\chi^{2}$ for proportions, Mann-Whitney $U$ test for continuous variables.

Values in bold typeface are statistically significant at $p<0.05$.

CMV, conventional mechanical ventilation; CPAP, continuous positive airway pressure; CPR, cardiopulmonary resuscitation; $\mathrm{FiO}_{2}$, fractional inspired oxygen; GA, gestational age; HFOV, high-frequency oscillatory ventilation; NICU, neonatal intensive care unit; ROC, redirection of care.

palliative care for infants born at 22-23 weeks of gestation and active obstetrical and neonatal interventions at 25 weeks of gestation. At 24 weeks, an individualised

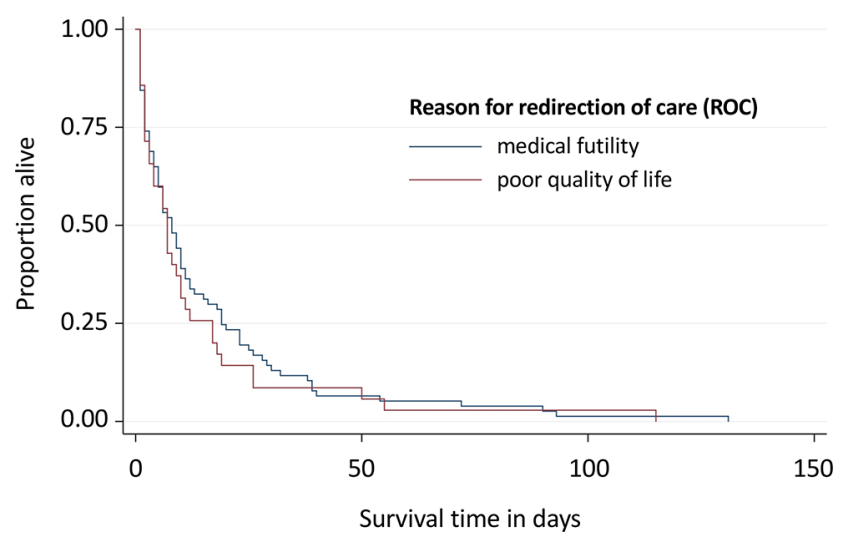

Figure 2 Kaplan-Meier survival curves for infants admitted to the NICU $(n=129)$ : redirection of care $(R O C)$ because of medical futility ( $n=89$ ) versus ROC because of anticipated poor quality of life $(n=36)$ (information on reason for ROC missing for three patients). NICU, neonatal intensive care unit. approach based on additional prognostic factors is recommended. ${ }^{20}$

Our data indicate that once infants had been admitted to an NICU, intensive care was provided without a priori restriction. In contrast to decision-making in the DR, GA was no longer an important factor when caregivers and parents had to decide between ongoing intensive care or ROC in the NICU. The intensity of life-sustaining therapies used also suggests that limitation (ie, withholding) of intensive care measures was uncommon. However, when such therapies appeared to fail (mentioned in $65 \%$ of patients) or, less commonly, concerns regarding the future quality of life became important (mentioned in $29 \%$ of patients), life-sustaining therapies, were withdrawn in most patients.

Previous single-centre reports from Switzerland analysing deaths of both preterm and term infants have documented high rates of primary non-intervention among infants dying in the $\mathrm{DR}^{212}$ and high rates of end-of-life decision-making for infants dying in the NICU. ${ }^{21-23}$ Deaths despite maximum intensive care were 
Table 4 Principal cause of death and survival time in days of infants admitted to the NICU ( $n=129)$

\begin{tabular}{lllll}
\hline Principal cause of death & $\mathbf{n}$ & Days & $\mathbf{7 5 \%}$ died \\
\hline Severe congenital malformations & 27 & $\mathbf{2 5 \%}$ died & $\mathbf{5 0 \%}$ died & 11 \\
Sepsis & 24 & 2 & 6 & 12 \\
Cardiovascular failure & 21 & 3 & 6 & 17 \\
Respiratory failure & 21 & 1 & 8 & 16 \\
Gastrointestinal complication & 19 & 3 & 19 & 28 \\
Neurological complication & 8 & 6 & 1 & 7 \\
\hline
\end{tabular}

In nine cases, principal cause of death could not be determined.

$\mathrm{NICU}$, neonatal intensive care unit.

much less common and were described for $3 \%-11 \%$ of all DR deaths and $8 \%-21 \%$ of all NICU deaths. In an international study from four perinatal centres in three different countries (USA: Chicago, Milwaukee; Canada: Montreal and the Netherlands: Groningen), Verhagen et al observed striking differences in neonatal end-oflife decision-making and circumstances of death. ${ }^{30}$ In Chicago, there were no DR deaths, no ROC for quality of life reasons, and $31 \%$ of NICU deaths occurred following CPR attempts. In contrast, in the three other centres, DR deaths were described in $16 \%-22 \%$, elective extubation for quality-of-life reasons occurred in 19\%-35\% of NICU deaths and CPR was uncommon (4\%-12\%). Obviously, neonatal end-of-life decisions are not only evidence based but vary widely between countries ${ }^{31}$ and can be significantly affected by an individual NICU's culture. ${ }^{30} 3233$

In our study, the age at death was influenced by the principal failing organ system but not by the reason for ROC. This observation is consistent with the results from a recently published large study from the USA, which also found timing of death was cause-specific. ${ }^{34}$ With increasing awareness that end-of-life decision-making is associated with significant uncertainty, ${ }^{29} 35$ several reports have documented that deaths of patients in the NICU in recent years occurred later than in the past. ${ }^{33} 36$

ELGANs who died in the DR after live birth (both after late termination of pregnancy and following spontaneous labour or induction of labour for maternal reasons or with the objective to increase chances of infant survival) rarely received drugs to relieve pain and suffering, whereas more than $50 \%$ of patients who died in the NICU received opiates and/or benzodiazepines. Available evidence from the literature suggests that this is a common phenomenon not restricted to preterm infants. ${ }^{36-38}$ More recently, however, Durrmeyer et al found much higher rates of pharmacological palliation among $73 \mathrm{DR}$ deaths from the more recent EPIPAGE-2 cohort, with 35 infants receiving some form of comfort medication, primarily in an attempt to diminish gasping. ${ }^{39}$

Our study has several limitations: data collection was restricted to the Swiss level III perinatal centres and we may have missed some ELGANs who have died at lower level institutions. However, this number is likely to be small because antenatal referral of high-risk pregnancies is well established in Switzerland. Even though almost 600 deaths were included in the study, the sample size is too small to allow for centre comparison. Medical records are hospital specific and non-uniform; data quality is, therefore, likely to vary.

\section{Conclusions}

In Switzerland, most deaths among infants born at less than 24 weeks of gestation occurred in the DR. The decision for primary non-intervention appeared to be primarily based on GA. In contrast, most deaths of ELGANs with a GA $\geq 24$ weeks were observed following unrestricted provisional intensive care, end-of-life decision-making and ROC in the NICU regardless of the degree of immaturity.

Collaborators The Swiss Neonatal End-of-Life Study Group includes the following local collaborators: P Meyer, C Anderegg (Kinderklinik, Kantonsspital Aarau, Aarau,

Switzerland), 0 Ahrens, M Nelle, D Grütter (Abteilung für Neonatologie, Frauenklinik und Medizinische Kinderklinik, Bern, Switzerland), S Schulzke (Abteilung für Neonatologie, Universitäts-Kinderspital beider Basel, Basel, Switzerland), B Wagner (Abteilung für Intensivpflege, Universitätskinderklinik, Inselspital, Bern, Switzerland), W Bär, Y Cajochen (Kinderklinik, Kantonsspital Graubünden, Chur, Switzerland), M Roth-Kleiner, JF Tolsa (Département de Pédiatrie, CHUV, Lausanne, Switzerland), J Cotting (SI Pédiatriques et Médico-Chirurgicaux, CHUV, Lausanne, Switzerland), A Malzacher (Klinik für Geburtshilfe und Gynäkologie, Kantonsspital St. Gallen, St. Gallen, Switzerland), G Jäger (Intensivpflege- und Frühgeburtenstation, Ostschweizer Kinderspital, St. Gallen, Switzerland), B Frey (Abteilung für Intensivmedizin und Neonatologie, Universitätskinderklinik Zürich, Zürich, Switzerland).

Contributors TMB has developed the research protocol, coordinated and supervised on-site data collection, analysed the data, drafted the first version of manuscript and finalised the manuscript for submission. MAS has developed the secure online database, was responsible for statistical analyses of the data and was involved in discussions of the results and revision of the manuscript draft. MA served as liaison to the Swiss Neonatal Network, was involved in data quality assessment and revision of the manuscript draft. HUB and JCF were involved in the development of the research protocol, obtaining ethics approval of the study, discussions of the results and revision of the manuscript draft. RB-H, REP and DB were involved in discussions of the results and revision of the manuscript draft. All authors have approved the final version of the manuscript.

Funding This work was supported by grant no $406740 \_139303$ of the Swiss National Research Foundation (SNRF NRP 67 Project 'End-of-Life').

Competing interests None declared.

Ethics approval Data collection and evaluation for this study were approved by the Swiss Federal Commission for Privacy Protection in medical research and the Swiss ethical review boards (KEK-ZH-Nr2014-0551 and KEK-ZH-Nr2014-0552). 
The patients' representatives were informed about the use of deidentified data for research.

Provenance and peer review Not commissioned; externally peer reviewed.

Data sharing statement Additional data are available by emailing tmberger@ bluewin.ch

Open Access This is an Open Access article distributed in accordance with the Creative Commons Attribution Non Commercial (CC BY-NC 4.0) license, which permits others to distribute, remix, adapt, build upon this work non-commercially, and license their derivative works on different terms, provided the original work is properly cited and the use is non-commercial. See: http://creativecommons.org/ licenses/by-nc/4.0/

(c) Article author(s) (or their employer(s) unless otherwise stated in the text of the article) 2017. All rights reserved. No commercial use is permitted unless otherwise expressly granted.

\section{REFERENCES}

1. Doyle LW, Roberts G, Anderson PJ, et al. Outcomes at age 2 years of infants $<28$ weeks' gestational age born in Victoria in 2005. J Pediatr 2010;156:49-53.

2. Horbar JD, Badger GJ, Carpenter JH, et al. Trends in mortality and morbidity for very low birth weight infants, 1991-1999. Pediatrics 2002;110:143-51.

3. Meadow W, Lee G, Lin K, et al. Changes in mortality for extremely low birth weight infants in the 1990s: implications for treatment decisions and resource use. Pediatrics 2004;113:1223-9.

4. Stevenson DK, Wright LL, Lemons JA, et al. Very low birth weight outcomes of the National Institute of Child Health and Human Development Neonatal Research Network, January 1993 through December 1994. Am J Obstet Gynecol 1998;179:1632-9.

5. Neonatal medicine - Nuffield Bioethics. http://nuffieldbioethics.org/ project/neonatal-medicine/ (accessed 11 Aug 2016).

6. Hussain N, Rosenkrantz TS. Ethical considerations in the management of infants born at extremely low gestational age. Semin Perinatol 2003;27:458-70.

7. Lorenz JM. Management decisions in extremely premature infants. Semin Neonatol 2003;8:475-82.

8. Tyson JE, Stoll BJ. Evidence-based ethics and the care and outcome of extremely premature infants. Clin Perinatol 2003;30:363-87.

9. Peabody JL, Martin GI. From how small is too small to how much is too much. Ethical issues at the limits of neonatal viability. Clin Perinatol 1996;23:473-89.

10. Berger TM, Büttiker V, Fauchère J-C, et al. Recommendations for the care of infants born at the limit of viability. Schweiz Ärzteztg 2002;83:1589-95.

11. Management of the woman with threatened birth of an infant of extremely low gestational age. fetus and Newborn Committee, Canadian Paediatric Society, Maternal-Fetal Medicine Committee, Society of Obstetricians and Gynaecologists of Canada. CMAJ 1994;151:547-53.

12. Lui K, Bajuk B, Foster K, et al. Perinatal care at the borderlines of viability: a consensus statement based on a NSW and ACT consensus workshop. Med J Aust 2006;185:495-500.

13. MacDonald $\mathrm{H}$; American Academy of Pediatrics. Committee on Fetus and Newborn. Perinatal care at the threshold of viability. Pediatrics 2002;110:1024-7.

14. Pignotti MS, Scarselli G, Barberi I, et al. Perinatal care at an extremely low gestational age (22-25 weeks). An Italian approach: the "Carta di Firenze". Arch Dis Child Fetal Neonatal Ed 2007;92:F515-6.

15. Gemeinsame Empfehlung der. Deutschen Gesellschaft für. Gynäkologie und Geburtshilfe. der Deutschen Gesellschaft für Kinderheilkunde und Jugendmedizin. der Deutschen Gesellschaft für Perinatale Medizin. der Gesellschaft für Neonatologie und Pädiatrische Intensivmedizin. [Premature birth at the boundary of infant viability]. Z Für Geburtshilfe Neonatol 2008;212:109-13.

16. Wilkinson AR, Ahluwalia J, Cole A, et al. Management of babies born extremely preterm at less than 26 weeks of gestation: a framework for clinical practice at the time of birth. Arch Dis Child Fetal Neonatal Ed 2009;94:F2-5.

17. Guillén Ú, Weiss EM, Munson D, et al. Guidelines for the management of extremely premature deliveries: a systematic review. Pediatrics 2015;136:343-50.

18. Berger TM, Steurer MA, Woerner A, et al. Trends and centre-tocentre variability in survival rates of very preterm infants $(<32$ weeks) over a 10-year-period in Switzerland. Arch Dis Child Fetal Neonatal Ed 2012;97:F323-8.

19. Fischer N, Steurer MA, Adams M, et al. Survival rates of extremely preterm infants (gestational age <26 weeks) in Switzerland: impact of the Swiss guidelines for the care of infants born at the limit of viability. Arch Dis Child Fetal Neonatal Ed 2009;94:F407-13.

20. Berger TM, Bernet V, El Alama S, et al. Perinatal care at the limit of viability between 22 and 26 completed weeks of gestation in Switzerland. 2011 revision of the Swiss recommendations. Swiss Med Wkly 2011;141:w13280.

21. Arlettaz R, Mieth D, Bucher HU, et al. End-of-life decisions in delivery room and neonatal intensive care unit. Acta Paediatr 2005;94:1626-31.

22. Berger TM, Hofer A. Causes and circumstances of neonatal deaths in 108 consecutive cases over a 10-year period at the Children's Hospital of Lucerne, Switzerland. Neonatology 2009;95:157-63.

23. Berner ME, Rimensberger PC, Hüppi PS, et al. National ethical directives and practical aspects of forgoing life-sustaining treatment in newborn infants in a Swiss intensive care unit. Swiss Med Wkly 2006;136:597-602

24. Bottoms SF, Paul RH, lams JD, et al. Obstetric determinants of neonatal survival: influence of willingness to perform cesarean delivery on survival of extremely low-birth-weight infants. National Institute of Child Health and Human Development Network of Maternal-Fetal Medicine Units. Am J Obstet Gynecol 1997;176:960-6.

25. Rysavy MA, Marlow N, Doyle LW, et al. Reporting outcomes of extremely preterm births. Pediatrics 2016;138.

26. Perlbarg J, Ancel PY, Khoshnood B, et al. Delivery room management of extremely preterm infants: the EPIPAGE-2 study. Arch Dis Child Fetal Neonatal Ed 2016;101:F384-90.

27. Janvier A, Lantos J. Delivery room practices for extremely preterm infants: the harms of the gestational age label. Arch Dis Child Fetal Neonatal Ed 2016;101:F375-6.

28. Seri I, Evans J. Limits of viability: definition of the gray zone. J Perinatol 2008;28(Suppl 1):S4-8.

29. Singh J, Fanaroff J, Andrews B, et al. Resuscitation in the "gray zone" of viability: determining physician preferences and predicting infant outcomes. Pediatrics 2007;120:519-26.

30. Verhagen AA, Janvier A, Leuthner SR, et al. Categorizing neonatal deaths: a cross-cultural study in the United States, Canada, and the Netherlands. J Pediatr 2010;156:33-7.

31. De Leeuw R, Cuttini M, Nadai M, et al. Treatment choices for extremely preterm infants: an international perspective. J Pediatr 2000;137:608-16.

32. Berger TM. Decisions in the gray zone: evidence-based or culturebased? J Pediatr 2010;156:7-9.

33. Dupont-Thibodeau $A$, Langevin $R$, Janvier $A$. Later rather than sooner: the impact of clinical management on timing and modes of death in the last decade. Acta Paediatr 2014;103:1148-52.

34. Patel RM, Kandefer S, Walsh MC, et al. Causes and timing of death in extremely premature infants from 2000 through 2011. N Engl J Med 2015;372:331-40.

35. Meadow W, Frain L, Ren Y, et al. Serial assessment of mortality in the neonatal intensive care unit by algorithm and intuition: certainty, uncertainty, and informed consent. Pediatrics 2002;109:878-86.

36. Koper JF, Bos AF, Janvier A, et al. Dutch neonatologists have adopted a more interventionist approach to neonatal care. Acta Paediatr 2015;104:888-93.

37. Garten L, Glöckner S, Siedentopf JP, et al. Primary palliative care in the delivery room: patients' and medical personnel's perspectives. $J$ Perinatol 2015;35:1000-5.

38. Janvier A, Meadow W, Leuthner SR, et al. Whom are we comforting? an analysis of comfort medications delivered to dying neonates. $J$ Pediatr 2011;159:206-10.

39. Durrmeyer X, Scholer-Lascourrèges C, Boujenah L, et al. Delivery room deaths of extremely preterm babies: an observational study. Arch Dis Child Fetal Neonatal Ed 2017;102:F98-103. 